\title{
The Fruit Fly Drosophila as a Powerful Tool in Teaching Life Sciences in Middle and High School Classrooms
}

\author{
Jari Intra and Maria Enrica Pasini \\ Department of Biosciences, University of Milano, via Celoria 26, Milano 20133, Italy. \\ Tel.: +3902 50314887; fax: +3902 50314881. E-mail address: jari.intra@unimi.it
}

\begin{abstract}
Living organisms can be used as important didactic tools for students, and we report here for the first time the evaluation of a scientific laboratory on Drosophila. The aim of this work is to attract more students towards science disciplines and a real appreciation for animal kingdom. We aimed to capture students' interest, develop important educational experiences, and promote the basic and integrated science process skills that are involved in scientific inquiry, including direct contact to a living organism and authentic research on Drosophila melanogaster. We performed this experience in non-selective middle (100 students) and high school classrooms (200 students). The practical activities were carried out over three months. Initially, we decided to make homemade fly traps to catch flies, so that students could observe, recognize and have a direct contact with Drosophila. Several experiences were performed, such as the evaluation of different methods for immobilizing flies, and the observation of life cycle, sexual dimorphism, Drosophila mutants plus several species of Drosophilidae. Moreover, students prepared a procedure for fly food, and a method for anesthetizing flies. With sample questionnaires, we obtained a survey of the experiences and so we observed a general agreement and a broad consensus (82 \%), since students considered the experiences very stimulating. As a final result we obtained that students improved their attitudes towards science.
\end{abstract}

Keywords - Fruit Fly, Laboratory, Model Organism, Science.

\section{INTRODUCTION}

"The power of science without the control of compassion and admiration for life is too immense to be applied merely for the satisfaction of scientific curiosity. If Biology was taught in a manner that developed a sense of wonder and of reverence for life, and if students felt inwardly enriched from their study of life, these students would formulate as a life-long goal the steadfast determination to protect and preserve all life and would bring healing to a world desperately in need of it" [1]. Starting from this central consideration, our goal was to promote that biological studies involving animals are necessary and an important phase of understanding living processes. In fact, recognizing the importance of student science education, scientists, educators, and policy leaders have issued dozens of reports, over the past several decades, calling for dramatic alterations to student curricula and teaching methods, and proposed that students should learn about the nature of science and engage in scientific practices (American Association for the Advancement of Science [AAAS], 2011) [2].
Moreover, incorporating direct contact of living organisms and authentic research experiences in biology laboratory increases in the students the interests towards the life, the discovery and the rigor of scientific processes [3]-[4]. Working to reach these purposes, model organisms have been often used in the classroom to help students to learn important concepts in various disciplines. Each discipline has its own set of organisms that have proven to be most suitable to use. For example, the bacterium Escherichia coli and the dipteran Drosophila melanogaster have been used productively as model organisms in introductory biology courses to teach microbiology and genetics.

There are three evident advantages of using animal as model organisms in teaching biology. First, the model organism's immediate response to the change of environment will enhance students' learning and help keeping their curiosity, interest, and concentration. In addition, students not only understand what they see, but they also recognize that it is real [5]-[6]. Secondly, the use of model organisms involves hands-on activities that offer unique experiences that could not be obtained through other teaching methods [7]. Thirdly, working with model organisms, students are able to develop the comprehension of a scientific concept, the nature of scientific inquiry, scientific methods, and skills necessary to become independent inquiries. Furthermore, they will come to understand the investigative nature of the scientific originality, including how to analyze survey data [6]-[8] [9]. These advantages could be obtained using any living organism. However, model organisms are well-established experimental systems, having certain properties, and being suitable to classroom use [10]-[11].

In many classes, the students never saw a living organism. The fruit fly, Drosophila melanogaster, is the most popular eukaryotic organism used in classrooms to teach Life sciences [12]. It is used in heredity and biomedical research, where the aims are to understand human genetics and developmental processes. It is also a popular model for teaching Mendelian genetics. Drosophila is a very popular and successful model organism; it has a short life cycle of two weeks, making it possible to study numerous generations in a scholastic year [13]-[14]-[15]. It is easy to culture and relatively inexpensive to house large numbers [13]-[15]-[16]. Its size is suitable to cultivation in school laboratories. In addition, it is large enough that many features can be seen with the naked eye or under low-power magnification [14]. In addition, there are many useful tools to facilitate the study of genetics. For example, some researchers used 
Drosophila to study how a set of homeotic genes controlled its body plan [14, 17]. Indeed, Drosophila is used for many classroom disciplines, such as classical and molecular genetics [15]-[17]-[18].

Practical work is commonly used from many middle and high school science teachers [9]-[19], since it is essential to improve the interest in students towards studying science, and the excitement of research experiences [20]-[21]-[22]. In fact, practical work is one of the methods of teaching and learning science that students found as the "most enjoyable" [21]-[22].

In this activity, in order to attract more students to science disciplines and to a real appreciation for animal kingdom, our goal was to capture student interest, to develop important educational experiences, and to promote the basic and integrated science process skills that are involved in scientific inquiry, including direct contact to a living organism and authentic research experiences on Drosophila melanogaster. This scientific experience spanned for three months, from April to June, filling one 6-h lab session every two week. The classroom(s), divided into small groups of three students, followed several labbased learning activities on Drosophila, from capturing the fruit flies to observing life cycle, sexual dimorphism, mutants (principles of genetics), different drosophilidae species, different methods to "knock-out" fruit flies, and preparation of fly food. Finally, we evaluated the effectiveness of this practical work in enhancing the development of conceptual understanding and in motivating students to pursue a science education.

\section{MATERIALS AND METHODS}

\section{Students}

We have performed this scientific laboratory to 300 students: one hundred students (55 males, 45 females) belonging to four classrooms attending third year of middle school, and two hundred students (93 males, 107 females) belonging to eight classrooms attending third year of scientific high school.

\section{How to Capture Fruit Fly}

Fruit flies are attracted to processes associated with fermentation and decaying of fruits and vegetables. To allow the students a first approach to Drosophila, we tried using simple and inexpensive fruit fly traps. We prepared two different fruit fly traps. At the beginning, we added $1 / 4$ cup of warm (not boiling) water into two glass jars. Then, in the first glass jar, we added one teaspoon of yeast and one teaspoon of sugar, while in the second glass jar we added pieces of banana or apple. Later, over the mouth of jars we placed small plastic bags with a corner reaching into the jar and a small hole in the corner. We secured the bags around the rims with two rubber band. Each group of students had two traps. These traps were placed in the garden, and flies that were attracted, crawled down the plastic, through the hole and then into the jars. Once captured, most of them were not able to find their way back out.

How to Use Drosophila

In this work, we used five different species of drosophilids, Drosophila melanogaster, Drosophila yakuba, Drosophila simulans, Drosophila ananassae, and Drosophila virilis, while white-eyed mutants were obtained as a gift of Dr. Maria Enrica Pasini (University of Milan). In our experiments, we used only adult flies that are more difficult to treat than embryos and larvae. Because the adults can fly, they need to be anesthetized before you count, sex, or genetically type them. There are several ways to do this: (1) Putting flies on ice to immobilize them. Using reusable commercial ice pack(s), that is covered with a piece of filter paper which absorbs the condensed water formed on the cold surface, flies can be knocked at least $1 \mathrm{~h}$ [23]. (2) Most research labs use $\mathrm{CO}_{2}$ (carbon dioxide). It is a simple method, but it needs a set-up with tanks, regulators, and tubing, so this could be not used in the classroom. (3) Commercial anaesthetics, such as FlyNap ${ }^{\circledR}$ that is extremely easy to use in the classroom. It comes as a vial of fluid with about eight sticks. These wands must beimmersed in the fluid, then in the vial where flies are active. An exposure time of <1 minute knocks flies out for at least 30 minutes. FlyNap ${ }^{\circledR}$ is non-toxic (active ingredient $=$ trimethylamine), but it has a very strong negative effect that can irritate. For this reason, you should always use FlyNap $^{\circledR}$ under a fume hood. (4) Anesthetization of the flies using ether. Etherisation knock flies out but requires a training period for the students because ether could kill flies by overetherisation. In addition, ether requires a fume hood. (5) Commercial $\mathrm{CO}_{2}$ : the method used in this work is a simple case of an acid-base reaction where sodium bicarbonate $\left(\mathrm{NaHCO}_{3}\right)(10 \mathrm{~g}$ in a glass jar) reacts with acetic acid $\left(\mathrm{C}_{2} \mathrm{H}_{4} \mathrm{O}_{2}\right)(10 \mathrm{ml})$ of vinegar in order to produce an intermediate product known as carbonic acid $\left(\mathrm{H}_{2} \mathrm{CO}_{3}\right)$. The intermediate decomposes, and it is converted into $\mathrm{CO}_{2}$ gas, which rapidly escapes from the solution, allowing the anesthetization of fruit flies for at least 30 minutes. They are contained in a glass jar covered with a gauze and secured with one rubber band (Fig. 1).

\section{How to Sex Drosophila}

Drosophila males are easily distinguished from females. Males are smaller than females, and in addition, they have dark, rounded genitalia at the tip of their abdomen, whereas females have light, pointed genitalia and brown stripes across the back of their abdomen. The males also have a unique characteristic on their forelegs, the sex comb. The sex comb is a small patch of bristles visible on the forelegs of the male. The sex of flies can be distinguished analysing the external genitalia under magnification. It is important to be aware of this feature, because genetics experiments require "virgin" females for the first cross. To obtain virgin flies, students must separate males from females within 2 hours since the emergence from the pupa.

\section{How to Feed Drosophila}

In nature, fruit flies adult and larvae are attracted to processes associated with fermentation and breed in decaying fruits and vegetables. In laboratory, fly food is based on some fruit types, such as banana or apple. Other ingredients include cornmeal, corn syrup or molasses for extra sugar, ethanol, yeast, and gelatine. Although it is 
easy to prepare this food, we wanted the students to write a procedure for the preparation of fly food starting from these ingredients: agar (for the solidification), cornmeal, sugar, yeast, fruit (apple or banana or pear), and propionic acid (to prevent bacterial growth).

\section{How to Maintain Drosophila}

Fruit flies are extremely low-maintenance. Once they are in a vial with food, they do not need additional food or water. Nevertheless, as adults can reproduce throughout their life, the vials become full. Therefore, the best way to maintain flies is to move groups of adults to fresh vials every two weeks.

Flies like warm temperatures, and if an incubator is available, it is ideal to keep them at a constant $25^{\circ} \mathrm{C}$. In a classroom, it is important to keep fruit flies in a part of the classroom that stays at a relatively constant temperature. If the temperature downs below to $22^{\circ} \mathrm{C}$, flies may slow their development.

\section{Methodology of Assessment}

This laboratory work was evaluated in two ways. First, every day we submitted a questionnaire with three closedended questions (yes or not) to know if student enjoyed the experience, if student understood it, and if student would have repeated it. Second, at the end of the scientific course, students were asked to rate their agreement with five different possibilities for each session: 1, strongly disagree: completely negative impact of the course; 2 , disagree: decrease the student's motivation to engage the course-based research or created negative feelings toward doing science; 3, neutral: no effect on the student's motivation or attitude toward doing science; 4, agree: increase the student's motivation towards research or attitude toward doing science; 5, strongly agree: completely positive impact of the course.

\section{Statistical Analysis}

MedCalc Statistical Software was used for statistical analysis (MedCalc Software bvba, Ostend, Belgium; http://www.medcalc.org; 2014) [24]. Chi square test was performed for the comparison of independent samples. A p value less than 0.01 was accepted to be statistically significant.

\section{ReSUlts}

This scientific experience spanned 12 week (from April to June), filling one 6-h lab session every two weeks. In every classroom where we carried out this work, students have been separated in cooperative groups of three; the main limitation was availability of stereo and light microscopes in the scientific laboratory.

On the first day, we started with two questions: Do you like bugs? Do you know Drosophila? Most of the students (about 90\%) do not know fruit fly, and generally, insects are unattractive organisms. For these reasons, we decided to begin with a stimulating idea "I want to see Drosophila, I want to capture it!' Fruit flies are attracted by sources of fermenting food, and in particular by the carbon dioxide [25]. Starting from yeast, fruits, water, and glass jars, and using their creativity students assembled fruit fly traps. Once prepared, they were placed in the garden or near a window. In about two days, these traps attracted flies, and when captured, most of them were not able to find the way to back out. Moreover, some female laid eggs, which hatched into maggots in a week. With great excitement and curiosity, students observed traps and the "life" of flies. In particular, they noted that some flies were not fruit flies. We consulted an entomologist that identified different flies, such as Musca domestica, Calliphora vicina, Phaenicia sericata, Musca sorbens, and Sarcophaga haemorrhoidalis.

In the second lesson, each group started to see a vial of Drosophila melanogaster, and all the students were invited to observe the features of the fruit flies. Initially, we described the life cycle of fruit fly: Drosophila undergo a four-stage life cycle: egg, larva, pupa and adult fly. Briefly, once fertilized, the embryo develops in the egg for around one day before hatching as larva. After hatching, the larva eats and grows quickly, moulting one day, two days, three days, and four days. Over five days, it pupates, and approximately in five days, it undergoes development before emerging as adult. Then, we proposed to the students some intriguing questions: How could we use this organism? How could we observe this organism under a stereomicroscope? How could we use this organism in research? All the students responded that it was necessary to sleep the fruit flies before its use. There are several ways to do this (see methodology), however only two methods could be used in a classroom. The first method was to immobilize fruit flies using reusable commercial ice pack(s), as described by Wen-hui, et al. [23]. The limitation of this procedure is the probable absence of ice packs in a school scientific laboratory. The second method was to anesthetize flies with $\mathrm{CO}_{2}$. Generally, at school, we do not have a set of tanks, regulators and tubing for the carbon dioxide use, since it is very expensive. So, how can we produce $\mathrm{CO}_{2}$ in a classroom? As described above in methodology, in this work we carried out a simple system using sodium bicarbonate and acetic acid (vinegar). Each group of students was invited to propose a mode to use these two reagents. Several proposals were prepared, and the scheme chosen was to use two glass jars and two gauzes (Fig. 1).

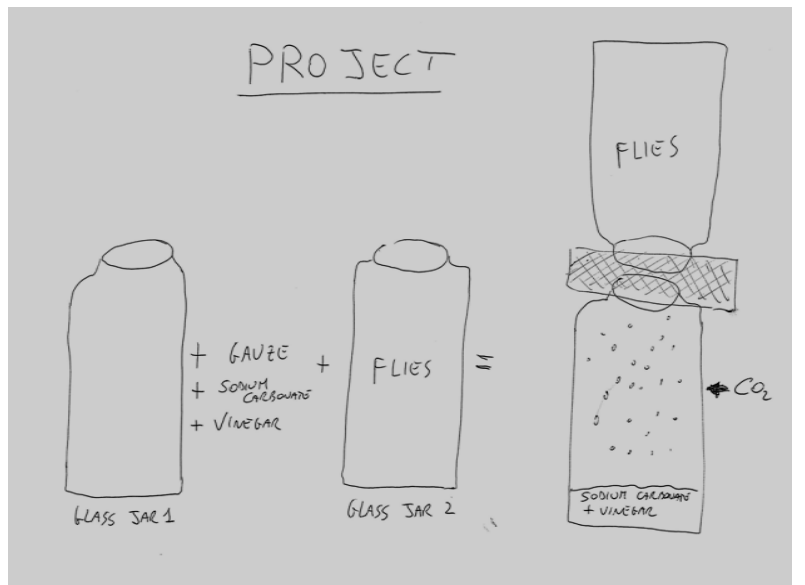

Fig. 1. Project proposed from a group of students for the anesthetization of fruit flies using sodium carbonate and vinegar. 
First vial contained sodium bicarbonate, and the second bottle contained fruit flies closed with a gauze. As soon as vinegar was poured, the bottle was covered with a gauze and the glass jar containing drosophilids was inverted on the first vial, since the production of $\mathrm{CO}_{2}$ was very quick. Immediately, knocked out drosophilids were sorted into petri dishes with lids to view under a stereomicroscope. Students moved the flies using a paintbrush; they identified males, females, their features, and separated them in two different vials (Fig. 2).
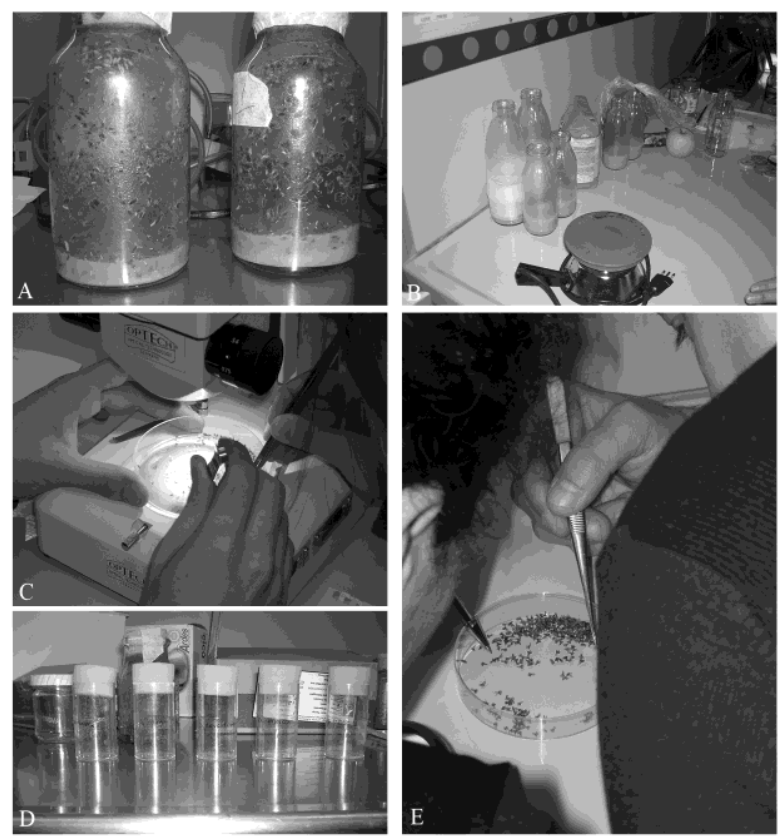

Fig. 2. Different moments of work with Drosophila during scientific experiences. (A): Vials used to observe the life cycle of Drosophila melanogaster; (B) Fly food recipes prepared by students; (C-E): Working with Drosophila, sexual dimorphism and white-eye mutants; (D): The vials of fruit fly species.

At the end, each group received a bottle containing a jelly-like food with male and females, five of each ones. Before the second lesson, students were invited to observe the life cycle during the next two weeks.

At the beginning of the third lesson, each student described what he/she observed on the life of fruit flies. In particular, it was highlighted that flies spend a lot of time eating. After this brief discussion, we decided to explore what they eat. In nature, adult fruit flies and larvae feed fermenting fruit or organic matter, since they are found around vineyards and orchards. In the past, lab flies were kept in vials containing rotting banana pulp; while nowadays, it is common practice to have bottles containing a jelly-like food that is typically made of a mix of water, cornmeal, yeast, sugar, and agar. The jelly needs to be hard enough so that the flies are not stuck in it, but soft enough for the larvae to crawl around and feed in. There are many variations on the basic formulation, indeed, we wanted that each group wrote a procedure for the preparation of fly food, starting from ingredients (see methodology) and different fruits (apple, banana, pear)
(Fig. 2). This experience was very interesting, intriguing and funny for all students, since they had the opportunity to perform an experiment, and dealing with any problems during and after it. Each group received two bottles containing fly food with two different types of fruit, and five males and females. In the following two weeks, students were asked to find out if fruit flies could or not have problems in nutrition. It was observed that flies did not have any problems of growth; however, a group noted the development of different molds in a glass jar, causing the death of fruit flies.

In nature, there are about 1,800 species of Drosophila[26]-[27], and they have been taxonomically classified. In this part, we wanted to know five of them Drosophila melanogaster, Drosophila yakuba, Drosophila simulans, Drosophila ananassae, and Drosophila virilis (Fig. 2). Initially, each group observed them and prepared a report about differences and similarities. It was noted that D. melanogaster, D. yakuba, D. simulans, and $D$. ananassae are very similar, as if they were identical, while D. virilis was extremely different, being larger and darker. Moreover, experiments to test the rate of development from egg to adult of the five fruit flies species were conducted. Typically, at room temperature $\left(24^{\circ} \mathrm{C}\right)$ the development time takes 10/12 days, however in nature it varies widely between species (between 7 and more than 60 days), and depends on the environmental factors, such as temperature, breeding substrate, and crowding. Students observed that, maintaining similar conditions of growth (food and temperature), the development periods of $D$. melanogaster, D. yakuba, D. simulans and D. ananassaewere comparable (between 10 and 13 days), while it increased to $15 / 16$ days for $D$. virilis. Why this difference? Students supposed that $D$. virilis is a bigger species, and therefore requires more time to grow.

In the fourth lesson, our goal was to understand the basic concepts of genetics and heredity, using a phenotypic trait of fruit fly simple and visible to students, which in our case was the colour of eyes. Initially, students learned the meaning of dominant and recessive mutation, and of autosomal or sex-linked mutation. Moreover, it was possible, using examples of inherited traits, such as hair, skin, and colour of eyes, to describe the terms genotype (genetic makeup of an organism) and phenotype (the way it express itself). Initially, we separated virgin females and males, and then we divided wild type and white-eyed (Fig. 2). We chose to cross white-eyed females $\left(X^{w} X^{w}\right)$ and wild red-eyed males type $\left(X^{+} Y\right)$ Vial "A" contained white-eyed females $\left(X^{w} X^{w}\right)$ and wild red-eyed males $\left(X^{+} Y\right)$, six of each; while in the vial "B" we crossed wild red-eyed females $\left(X^{+} X^{+}\right)$with whiteeyed males $\left(X^{w} Y\right)$, six of each. Starting from our experience and knowledge of genetics, we used the simple graphical way named Punnett Square to predict the phenotypic ratio of offspring. We put the genotype of male across the top and the female one down the left side. What phenotypes do you expect in the offspring? After two weeks, each group replied to this intriguing question.

In the last lesson, we discussed about the results of genetics' experiment. Each group separated females and 
males, presented results of phenotypes of their offspring, and proposed different possibilities. We have collected and discussed the data. In the offspring of $\mathrm{F}_{1}$ generation, we initially hypothesized in the vial " $A$ " the only presence of white-eyed males, conversely we also found some redeyed males. Moreover, in the vial "B" we found some white-eyed males, and not only wild-type males. Collectively, the conclusions were consistent with a sexlinked pattern of inheritance for the white-eyed mutation, and therefore, we briefly explained the Mendelian laws and the sex-linked inheritance discovered in the early 1900s by Thomas Hunt Morgan. However, a limiting factor was observed: to perform controlled crosses, students must collect adequate numbers of virgins. Even if students are trained to collect virgins, mistakes are usually made during the collection, in particular selecting nonvirgin females, confusing the expected phenotypes and results.

The assessment of the laboratory work was performed in two ways. First, in each session, students were given the option to evaluate the scientific experience with three closed-ended questions. Students showed interest and understanding, and they found useful the first, second, and third lesson (positive feedback from $91 \%$ to $100 \%$ ), while they reported, lower interest for the fourth and fifth lesson (positive feedback from $55 \%$ to $88 \%$ ). Statistical analysis indicated significant differences between the first three lesson and the last two $(\mathrm{p}<0.001)$ (Fig. 3).

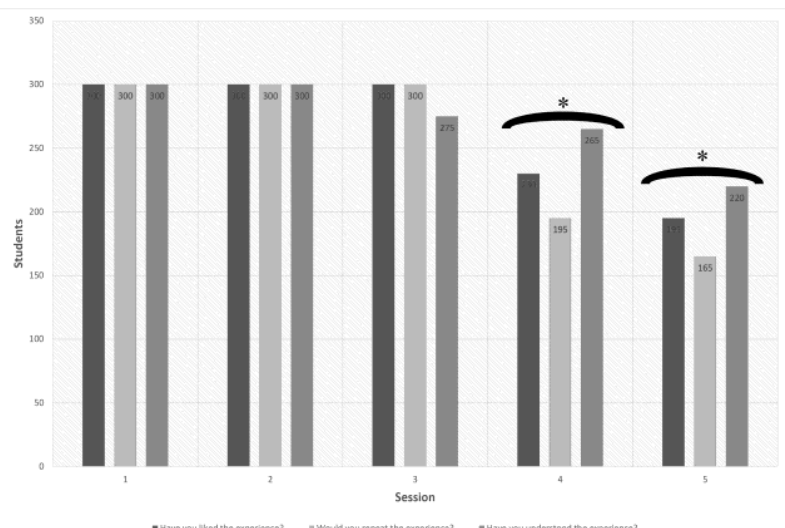

Fig. 3. Outcomes obtained from the questionnaires of each session. Students were asked to answer to three questions. The number of respondents for each application was 300 . Asterisks indicate statistical significant differences ( $\mathrm{p}<$ 0.001) between the first three lessons and the last two lessons.

Second, at the end of the scientific course, students were asked to rate their agreement for each session (Table I).

Table I: Summary data (\%) from the student questionnaire $^{\mathrm{a}}$

\begin{tabular}{lccccc}
\hline \multicolumn{7}{c}{ Work session } \\
\cline { 2 - 6 } & I & II & III & IV & V \\
\hline Completely disagree & 0 & 0 & 0 & 0 & 0 \\
Disagree & 0 & 0 & 0 & 10 & 17 \\
Neutral & 0 & 17 & 0 & 23 & 23 \\
Agree & 30 & 15 & 27 & 33 & 27 \\
Completely agree & 70 & 68 & 73 & 33 & 33 \\
\hline${ }^{a}$ Students were asked to rate their agreement for all lessons. The number of respondents in each \\
day was 300.
\end{tabular}

There was a broad consensus (agree + completely agree ranging from $60 \%$ to $100 \%$ ) upon the positive impacts of the first three sessions of this practical laboratory, in particular for the understanding of biological concepts, the completion of traditional textbook of introductory biology, for the curiosity and excitement captured. However, the fourth and the fifth part of the experience showed negative comments (neutral and disagree from $10 \%$ to $23 \%$ ), reflecting no detectable or negative impact of genetics on the students (Table I).

\section{Discussion}

Why are animals to be used in a scientific laboratory at school? One answer is that the first important educational objective is served by teaching respect for all forms of life. This purpose can start with learning about lower living forms including insects that, because of their shorter life, can provide excellent examples of the natural processes of aging and death. Students learn respect for all types of organisms observing their living, and the inevitability of death, that can be so easily accepted [3]. A second answer is to develop an understanding of animal care. The nutritional requirements, such as the food and the water, the environmental requirements, such as temperature and light, the interaction between animals can be seen as worthwhile objectives. Observing them, understanding their requirements for life, learning their diversity are important purposes that can be achieved only with living organisms and with direct contact. A third answer is that lessons that can be conducted without unnecessary and inconsistent trauma to the animals concerned provide a general appreciation and respect for living organisms [5].

Why a scientific laboratory is important in school classes? Scientists use their knowledge of natural scientific concepts, principles, theories, and laws together with a multiplicity of science processes, to construct new explanations concerning natural objects and phenomena [28]. Scientific inquiry refers to the activities of the students in which they are involved when they do science, as well as they have the opportunity of constructing meanings that are equivalent to explanations constructed by scientists, and to develop knowledge in a more significant way. Practical work is widely used as the basic modus operandi in teaching science [9]-[19]-[29]. Exposure to research experiences seems to attract more students towards science, technology, engineering, and mathematics (STEM) fields [2]-[22]. In fact, science laboratory promotes a wide variety of educational functions, including development of knowledge schemes [30], promotion of inquiry and problem solving [28], reflection of science as it is practiced by scientists [31], and development of skills in scientific processes [31]. Moreover, students, either individually or in small groups, are involved in manipulation and/or observation of real objects and materials, distinct by virtual objects and materials, such as those acquired from a DVD, a computer simulation, or even from literature [19]-[29]. As of 2013, the National Science Education Standards have been replaced by the Next Generation Science Standards 
(NGSS) [32] that proposed the laboratory activities to be performed in a way that students could use the following categories of skills: (a) formulate questions, (b) plan experiments, (c) carry out observations, (d) interpret and analyze data, (e) draw conclusions, (f) communicate, and (g) organize and implement a full investigation. A laboratory work can be divided into three phases: problems, methods, and solutions. That said, different levels of inquiry exist: (1) The problem and the methods are given to the student by the manual and students are asked to provide relationships they do not already know from their classroom studies; (2) The problem is given to the students, who must provide their own methods and solutions; (3) All phases of inquiry are left open to the student [9]. Indeed, engaging students in authentic research is a persistent recommended practice for teaching science to students [9]-[19]-[22]. Like realistic research experiences, inquiry-based approaches to classroom learning emphasize the evolving process of scientific thought, provide effective opportunities for students to increase confidence in their scientific performance and they see themselves as scientists, and it motivates students in continuing their scientific training. These approaches have been effective in promoting self-investment, raising enthusiasm for science, stimulating student interest, and increasing abilities in experimental design, data analysis, and application of initial biological knowledge. Furthermore, practical work offers important opportunities to link science concepts and theories with observations [33], however in order to be successful, students must be helped not only to do and see, but to think about their observations [34].

For all these reasons, in order to promote the attitude that living organisms, in this case the insects, are organic machines, to be manipulated to obtain a response, or to demonstrate a known phenomenon, and the dissemination of science disciplines and authentic research in a simple way, four years ago we decided to organise a practical work using a model system. Different animals are used as model [10]-[15]-[35], and Drosophila clearly is the insect in which biology is conceptually best understood [11][12]-[36]. Therefore, the current experience was based on Drosophila, as it possesses all the features of a model organism. It is a powerful tool in teaching Life Sciences and an effective pedagogical system to complement traditional lecture and textbook of introductory biology. Moreover, we started from this proposal: "It is only by providing the proper setting and exposure to animals that the scientist of tomorrow will be prepared to design and execute meaningful and human experiments on animals" [3]. Different experiments and approaches can be performed in a class using Drosophila, starting from inheritance and evolution to behaviour and health. There are many resources available online for inspiring practice and interesting ideas. The "Wonderful Fruit Fly" website is an important tool for seeing how Punnett square experiments can be carried out with fruit flies [37]. Recently, a multi-day exercise was designed to demonstrate concepts of inheritance and molecular evolution, allowing students to observe molecular evolutionary changes in class [38]. Furthermore, fruit flies can be used for behavioural experiments, in particular for food preference [39]-[40]. Other resources are available for experiment ideas to be performed in class, such as "How-to Fly Manual" and "Drosophila melanogaster in the classroom" blog [41]-[42]. In this work, we proposed different activities, ranging from direct observations and manipulations of Drosophila to experimental questions and techniques, in order to inspire students to pursue curiosity for a scientific method of investigation. Analysing the results of the student evaluations we can see that our approach to learning promote self-investment, raised enthusiasm for science, stimulate student interest, and enhance skills in experimental design, data analysis, and application of knowledge, as previously observed in other studies [43]-[44]-[45]-[46]. In particular, the first three lessons received major attention and student consensus. We assumed that lab experiences in working as a scientist increased enthusiasm, curiosity, and awareness of how fruit flies can be used in science. We also noted that students synthesized experimental results by critically evaluating data and drawing conclusions based on evidence and reasoning, engaged in formal scientific discourse, occupied in class by participating in activelearning exercises, refined their knowledge by participating in small-group activities that require discussion, and learned by reflecting on the effectiveness of their knowledge and problem-solving strategies.

Student's assessments indicated general agreement, since the laboratory course performed and proposed in this work was interesting, it increased understanding of a living organism used as a model organism in research, improved interest levels, and enhanced learning outcomes over and above textbook. However, the evaluation of genetic sessions remain controversial. Students are attracted from the "world" of DNA and inheritance; nevertheless, these scientific arguments could be improved and proposed in more sessions ( 3 or 4 ) and not only in one, in order to increase curiosity, interest, and learning. On the other hand, it is complicated to describe genetic concepts in a simple way, and we think that our approaches were easy to understand, however, improvements are needed to increase student understanding.

Collectively, our practical work suggested that dissemination of science to students through the direct observation and contact of living organism and authentic research experiences are needed to promote the reverence for all forms of life and to attract more students to science field, as also recently reported [2], and Drosophila allows instructors a way to do it. Moreover, when students go through new challenge in science, they will require abilities to study the problem, propose solutions, test their ideas and change their plans to come to a suitable conclusion. However, this is a skill of any profession and in life in general, not just in a scientific laboratory.

\section{ACKNOWLEDGMENT}

We would like to thank Prof. Caterina Fugazza and Dr. Annastella Gambini for the opportunity of collaboration in 
their classrooms, Dr. Cappellini Fabrizio for statistical analysis, and Dr. Intra Elena for reviewing the manuscript.

\section{REFERENCES}

[1] G.K. Russell. (1972). "Vivisection and the true aims of education in biology," American Biology Teacher, 34, pp. 254 257.

[2] American Association for the Advancement of Science [AAAS] (2011). Vision and Change in Undergraduate Biology Education: A call to Action, Washington, DC.

[3] W.J. Dodds. (1980). Learning from animals: Models for studying physiology and disease. In H. McGiffin \& N. Brownley (Eds.) Animals in education: Use of animals in high school biology classes and science fairs (pp. 23-26). Washington, DC: The Institute for the Study of Animal Problems.

[4] M.B. Emmons. (1980). Secondary and elementary school use of live and preserved animals. In H. McGiffin \& N. Brownley (Eds.), Animals in education: Use of animals in high schoo biology classes and science fairs (pp. 43-46). Washington, DC: The Institute for the Study of Animal Problems.

[5] H. McGiffin, and N. Brownley. (1980). Animals in education Use of animals in high school biology and science fairs Washington, DC: The Institute for the Study of Animal Problems.

[6] R.T. Manney, and L.M. Manney. (1992). "Yeast: a research organism for teaching genetics," American Biology Teacher, 54 pp. 426-431.

[7] N.A. Rowan. (1981). "Animal in education," American Biology Teacher, 43, pp. 280-282.

[8] R.T. Mertens. (1983). "Open-ended laboratory investigations with Drosophila," American Biology Teacher, 45, pp. 264-266.

[9] P.J. German, S. Haskins, and S. Auls. (1996). "Analysis of nine high school biology laboratory manuals: promoting scientific inquiry," Journal of Research in Science Teaching, 33, pp. 475499

[10] J.A. Bolker. (1995). "Model systems in developmental biology," BioEssays, 17, pp. 451-455.

[11] M.E. Pasini, F. Bertolotto, and P. Fasano. (2010). "The role of models in science: an experience with Drosophila," ProcediaSocial and Behavioral Sciences, 2, pp. 1164-1168.

[12] C. Sinadinos. (2009). "Science flies into the classroom with UK "researchers in Residence"," Bioscience education, 13, c3.

[13] C.D. Kramer. (1986). "The classroom animal - fruit flies," Science and Children, 4, pp. 30-33.

[14] W. Sofer, and L. Tompkins. (1994). "Genetics in the classroomdrosophila genetics in the classroom," Genetics, 136, pp. 417 422.

[15] C.M. Flannery. (1997). "Models in biology," American Biology Teacher, 59, pp. 244-248.

[16] W.A. Jeszenszky. (1997). "Managing the fruit fly experiment," American Biology Teacher, 59, pp. 292-294.

[17] M.G. Rubin. (1988). "Drosophila melanogaster as an experimental organism," Science, 240, pp. 1453-1459.

[18] A.A. Paloumpis. (2013). "The Use of Drosophila melanogaster in High School Genetics," The American Biology Teacher, 75, pp. $615-617$

[19] I. Abrahams, and M.J. Reiss. (2012). "Practical work: its effectiveness in primary and secondary schools in England,' Journal of Research in Science Teaching, 49, pp. 1035-1055.

[20] J. Wellington. (1998). Practical work in science. Time of reappraisal. In J. Wellington (Ed.), Practical work in school science: Which way now? (pp. 3-15). London: Routledge.

[21] B. Cerini, I. Murray, and M. Reiss. (2003). Student review of the science curriculum: Major findings, Planet science, London. Available at http://www.planetscience.com/sciteach/review/Findings.pdf

[22] R.M. Spell, J.A. Guinan, K.R. Miller, and C.W. Beck. (2014) "Redefining authentic research experiences in introductory biology laboratories and barriers to their implementation," $C B E$ Life Sciences Education, 13, pp. 102-110.

[23] Q. Wen-hui, Z. Tong-bo, and Y. Da-Xiang. (2015). “A Modified Cooling Method and its Application in Drosophila
Experiments," Journal of biological education, 49(3), pp. 302308.

[24] C. Stephan, S. Wesseling, T. Schink, and K. Jung. (2003) "Comparison of eight computer programs for receiver-operating characteristic analysis," Clinical Chemistry, 49, pp. 433-439.

[25] S. Wasserman, A. Salomon, and M.A. Frye. (2013). "Drosophila tracks carbon dioxide in flight," Current Biology, 23, pp. 301306.

[26] M. Ashburner, K.G. Golic, and R.S. Hawley. (2005). Drosophila: A Laboratory Handbook. (2nd ed.). Cold Spring Harbor Laboratory Press. pp. 162-164.

[27] I. Brake, and G. Bächli, (2008). Drosophilidae (Diptera). In World Catalogue of Insects, pp. 1-412.

[28] F.J. Rutherford, and A. Ahlgren. (1990). Science for all Americans. New York: Oxford University Press

[29] R. Millar. (2011). Practical work. In J. Osborne \& J. Dillon (eds.), Good practice in science teaching: What research has to say (pp. 108-134). Maidenhead: Open University Press.

[30] K.G. Tobin. (1990). "Research on science laboratory activities: In pursuit of better questions and answers to improve learning," School science and Mathematics, 90, pp.403-418.

[31] A. Hofstein, and V.N. Lunetta. (1982). "The role of the laboratory in science teaching: Neglected aspects of research,"Review of Educational Research, 52, pp. 201-217.

[32] Next Generation Science Standards [NGSS] Lead States. (2013) Next Generation Science Standards: For States, By States. Washington, DC: The National Academies Press.

[33] A. Hofstein, and V.N. Lunetta. (2004). "The laboratory in science education: Foundations for the twenty-first century," Science education, 88, pp. 28-54.

[34] R.F. Gunstone. (1991). Reconstructing theory from practical experience. In Wollnough B.E. (Ed.), Practical science (pp. $67-$ 77). Milton, Keynes: Open University Press

[35] M. Sugni, A. Barbaglio, F. Bonasoro, M. Gioria, P. Fasano, and M.E. Pasini. (2011). "The role of models in science: a multicomprehensive experience with the sea urchin Paracentrotus lividus," Procedia-Social and Behavioral Sciences, 93, pp. 1404-1408.

[36] D.R. Venema. (2006). "Enhancing undergraduate teaching and research with a Drosophila virginizing system," CBE-Life Science Education, 5, pp. 353-360.

[37] The Wonderful Fruti fly website: http://www.unc.edu/depts/our/hhmi/hhmift learning modules/fruitflymodule/index.html

[38] C.S.S. Heil, M.J. Hunter, J.K. Noor, K. Miglia, B. ManzanoWinkler, S.R. McDermott, and M.A. Noor, (2012). "Witnessing Phenotypic and Molecular Evolution in the Fruit Fly," Evolution,5(4), pp. 629-634

[39] R. Chhabra, S. Kolli, and J.H. Bauer. (2013). "Organically grown food provides health benefits to Drosophila melanogaster," PLoS One.8(1), e52988.

[40] K.M. Baudier, S.D. Kaschock-Marenda, N. Patel, K.L. Diangelus, S. O'Donnell, and D.R. Marenda. (2014). "Erythritol, a non-nutritive sugar alcohol sweetener and the main componen of truvia ${ }^{\circledR}$, is a palatable ingested insecticide," PLoS One.9(6), e98949.

[41] J. Roote, and A. Prokop, A. (2013). "How to design a genetic mating scheme: a basic training package for Drosophila genetics," G3 (Bethesda) 3, pp. 353-358.

[42] Drosophila melanogaster in the classroom" blog: http://www.drosophila.moonfruit.com

[43] C.J. Brame, W.M. Pruitt, and L.C. Robinson. (2008). "A molecular genetics laboratory course applying bioinformatics and cell biology in the context of original research," CBE Life Sciences Education, 7, pp. 410-421.

[44] D. Siritunga, M. Montero-Rojas, K. Carrero, G. Toro, A, Velez, and F.A. Carrero-Martinez. (2011). "Culturally relevant inquirybased laboratory module implementations in upper-division genetics and cell biology teaching laboratories," CBE Life Sciences Education, 10, pp. 287-297.

[45] D.J. Treacy, S.M. Sankaran, S. Gordon-Messer, D. Saly, R Miller, S.R. Isaac, and M.S. Kosinski-Collins. (2011). "Implementation of a project based molecular biology laboratory emphasizing protein structure function relationships in a large introductory biology laboratory course," CBE Life Sciences Education, 10, pp. 18-24. 
[46] E.A. Wiley, and N.A. Stover. (2014). "Immediate dissemination of student discoveries to a model organism database enhances classroom-based research experiences," CBE-Life Science Education, 13, pp: 131-138.

\section{Authors' Profiles}

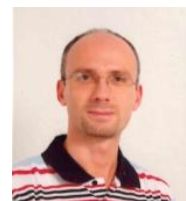

Jari Intra, Jari Intra received a Bachelor in biological sciences in 2000 at the University of Milan, Italy. In 2004, he earned a Ph.D in Cell Biology at the University of Pavia, Italy. He studied the proteins involved in gamete interactions in Drosophila. From 2004 to 2008 , he has done post-doctoral research on sperm-egg recognition in different drosophilids and Ceratitis capitata at the University of Milan, Italy. From 2008, he is involved in dissemination of science at middle and high school classrooms using Drosophila as model organism.

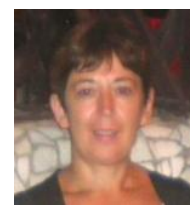

Maria Enrica Pasini, Maria Enrica Pasini is a permanent Associate Research Scientist, Department of Biosciences, University of Milan, Italy. She has carried out research on several aspects of the biology of reproduction in Drosophila. She is involved in educational projects of science communication and in dissemination of scientific culture among high-school students. 